\title{
Pulmonary Mucormycosis in a patient with Acute Myeloid Leukemia
}

Jonathan Pan, MD

Thomas Jefferson University, jonathan.pan@jefferson.edu

Margaret Kasner, MD

Thomas Jefferson University, Margaret.Kasner@jefferson.edu

Sheel Patel, MD

Thomas Jefferson University, sheel.patel@jefferson.edu

Gretchen Diemer, MD

Thomas Jefferson University, gretchen.diemer@jefferson.edu

Follow this and additional works at: https://jdc.jefferson.edu/tmf

Part of the Medicine and Health Sciences Commons

Let us know how access to this document benefits you

\section{Recommended Citation}

Pan, MD, Jonathan; Kasner, MD, Margaret; Patel, MD, Sheel; and Diemer, MD, Gretchen (2015) "Pulmonary Mucormycosis in a patient with Acute Myeloid Leukemia," The Medicine Forum: Vol. 16 , Article 12.

DOI: https://doi.org/10.29046/TMF.016.1.011

Available at: https://jdc.jefferson.edu/tmf/vol16/iss1/12

This Article is brought to you for free and open access by the Jefferson Digital Commons. The Jefferson Digital Commons is a service of Thomas Jefferson University's Center for Teaching and Learning (CTL). The Commons is a showcase for Jefferson books and journals, peer-reviewed scholarly publications, unique historical collections from the University archives, and teaching tools. The Jefferson Digital Commons allows researchers and interested readers anywhere in the world to learn about and keep up to date with Jefferson scholarship. This article has been accepted for inclusion in The Medicine Forum by an authorized administrator of the Jefferson Digital Commons. For more information, please contact: JeffersonDigitalCommons@jefferson.edu. 


\title{
Pulmonary Mucormycosis in a patient with Acute Myeloid Leukemia
}

\author{
Jonathan Pan, MD, Margaret Kasner, MD, Sheel Patel, MD, Gretchen Diemer, MD
}

\section{INTRODUCTION}

Mucormycosis is a rare fungal infection that is common amongst uncontrolled diabetics and immunocompromised patients. The most common clinical presentation is rhino-orbital-cerebral infection, which typically affects diabetics with ketoacidosis. ${ }^{1}$ Less commonly, pulmonary mucormycosis can occur in patients with hematologic malignancy, solid organ transplant and patients taking steroids or deferoxamine. The following report describes a 25-year-old male with Acute Myeloid Leukemia (AML) who developed a pulmonary mucormycosis infection. With a mortality rate of about $87 \%$, this case represents a favorable outcome for a rare and often lethal diagnosis.

\section{CASE DESCRIPTION}

A 25-year-old male with no past medical history presented to the hospital after two weeks of fatigue, shortness of breath and epistaxis. Lab work revealed leukocytosis with $43 \%$ blasts, anemia and thrombocytopenia. A bone marrow biopsy confirmed the diagnosis of AML. After admission, the patient developed persistent fevers and CT scan demonstrated ground-glass opacities in bilateral lung fields. Blood and sputum cultures, respiratory viral panel and acid fast studies were negative and the patient was started on antifungals and broad spectrum antibiotics. Bronchoscopy with bronchoalveolar lavage did not reveal an infectious source. The patient underwent induction chemotherapy with idarubicin and cytarabine, which was initially well tolerated. However, he soon developed neutropenic fever, hypoxia, and a non-productive cough. The treatment was broadened from vancomycin, zosyn and micafungin to meropenem and ambisome. Cultures remained negative during this time and subsequent imaging revealed right-middle and left-upper lobe consolidations with a central lucency.

\section{OUTCOME AND FOLLOW UP}

A CT-guided biopsy of the pulmonary consolidation was performed. Pathology revealed granulomatous inflammation with necrosis and silver stain showed sparsely septate hyphae consistent with mucormycosis. High-dose ambisome was initiated and the patient began to demonstrate signs of clinical improvement. He was discharged on a six-week course of intravenous ambisome. Follow-up imaging showed improvement of the consolidations and the patient was switched to oral posaconazle for six additional weeks.

\section{DISCUSSION}

Mucormycosis is a rare opportunistic fungal infection caused by fungi in the mucorales order, including mucor, rhizopus and absidia. ${ }^{3}$ These fungi are ubiquitous in nature, commonly found in soil and decaying matter and released via airborne spores. Histologically, hyphae are seen in broad, irregular branches with few septations, as opposed to aspergilli, which have acute branching angles and many septations. Comprising a unique category of angioinvasive molds, tissue infarction is a hallmark of the disease process. ${ }^{4}$ Risk factors include diabetes, hematologic malignancy, solid organ or stem cell transplant, immunocompromised state, iron overload and treatment with deferoxamine. ${ }^{5}$ While incidence is difficult to estimate due to mucormycosis not being a reportable disease, it is estimated that approximately 500 cases occur in the US each year. ${ }^{6}$ As rhino-orbital-cerebral infection is the most common clinical manifestation in diabetics, pulmonary mucormycosis is more commonly seen with hematologic malignancy, transplant patients and steroid or deferoxamine use. It is caused by direct inhalation of spores into bronchioles and alveoli, which presents as a rapidly progressing pneumonia with or without hemoptysis.? Clinical presentation is similar to that of other angioinvasive molds such as aspergillus or fusarium, and diagnosis is therefore obtained by culture and pathology. Imaging can show non-specific findings such as focal consolidation, nodules, masses, or pleural effusions. A halo sign on CT scan, which shows ground 
glass attenuation surrounding a nodule, is characteristic of pulmonary aspergillus. A reverse halo-sign, on the other hand, shows focal ground glass attenuation within a ring of consolidation and is more commonly seen with mucormycosis. As cultures are typically negative, tissue diagnosis is often pursued. A biopsy with silver stain will typically reveal broad, irregular, branching hyphae.

In cases where pulmonary mucormycosis is localized to a single lobe, surgical excision can be performed. However, first line treatment for pulmonary mucormycosis remains high-dose, intravenous amphotericin B. Liposomal amphotericin is preferred due to improved efficacy and safety, although renal function and electrolytes must nonetheless be carefully monitored. Treatment should be initiated for several weeks until the patient clinically improves. At this time, amphotericin may be switched to oral posaconzale, which is often continued for several months until attainment of both clinical and radiographic resolution.

\section{KEY POINTS}

This case represents a rare and difficult diagnosis of pulmonary mucormycosis in a patient with hematologic malignancy. While a rapidly progressive disease with a high mortality rate, the patient in this case experienced a favorable outcome. Diagnosis was made only after invasive testing and successful treatment was achieved with an extended course of high dose intravenous ambisome.

Cartoon by Eugene Han, MD

\section{REFERENCES}

1. Kauffman CA, Malani AN. Zygomycosis: an emerging fungal infection with new options for management. Curr Infect Dis Rep 2007; 9:435

2. Maertens J, Demuynck H, Verbeken EK, et al. Mucormycosis in allogeneic bone marrow transplant recipients: report of five cases and review of the role of iron overload in the pathogenesis. Bone Marrow Transplant 1999; 24;307

3. Kwon-Chung KJ. Taxonomy of fungi causing mucormycosis and entomophthoramycosis (zygomycosis) and nomenclature of the disease: molecular mycologic perspectives. Clin Infect Dis 2012; 54 Suppl 1:58

4. Greenberg RN, Scott LJ, Vaughn HH, Ribes JA. Zygomycosis (mucormycosis): emerging clinical importance and new treatments. Curr Opin Infect Dis 2004, 17:517

5. Roden MM, Zaoutis TE, Buchanan WL, et al. Epidemiology and outcome of zygomycosis: a review of 929 reported cases. Clin Infect Dis 2005 41;634

6. Kontoyiannis DP, Lewis RE. Agents of mucormycosis and Entomophthoramycosis. In: Mandell GL, Bennett GE, Dolin R, eds. Mandell, Douglas and Bennett's Principles and Practice of Infectious Diseases. 7th ed. Philadelphia, Pa: Churchill Livingstone; 2010:3257-69

7. Tedder M, Spratt JA, Anstadt MP, et al. Pulmonary mucormycosis results of medical and surgical therapy. Ann Thorac Surg 1994; $57: 1044$

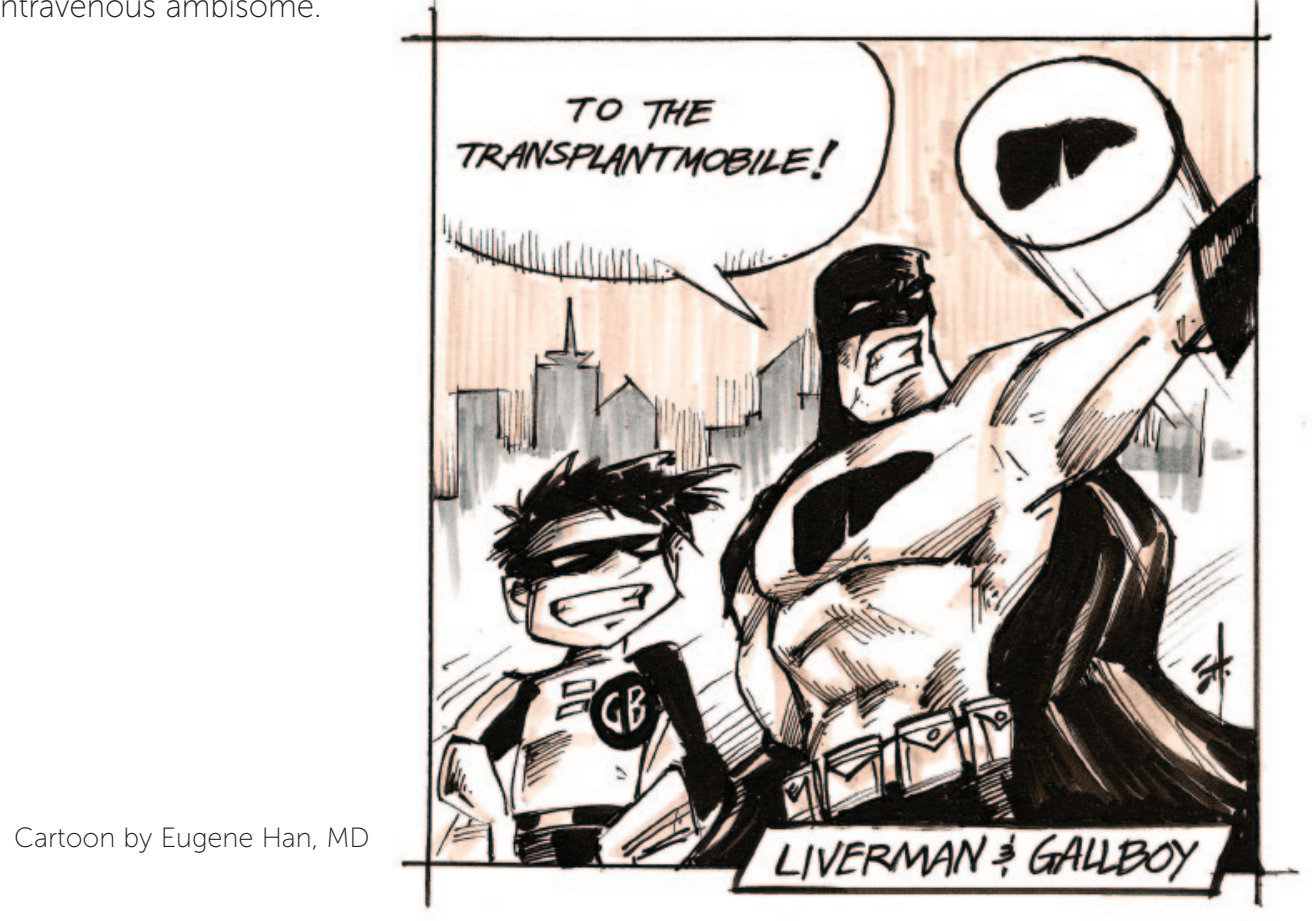

